\title{
A Novel Fast Voltage Sequence Component Detector of Unbalanced Three-Phase System
}

\author{
Baohong Jiang ${ }^{1}$ and Xinian $\mathrm{Li}^{2}$ \\ ${ }^{1}$ School of Foreign languages, Shandong Technology and Business University, Yantai 264005, China \\ ${ }^{2}$ School of Information and Electronic Engineering, Shandong Technology and Business University, \\ Yantai 264005, China
}

\begin{abstract}
The fast and accurate voltage sequence component detection of unbalanced three-phase system is of major importance for the industrial continuous processing. The traditional method is to calculate the voltage in $d q$ synchronous reference frame. This results in low order harmonics and long detection time. A novel fast voltage sequence components detector is proposed in this paper. It is to calculate the sequence component projection on $d q$ rotating reference frame with $\mathrm{h}$ times the fundamental angular velocity. Simulation results demonstrate the validity of the algorithm.
\end{abstract}

\section{INTRODUCTION}

Voltage sags are one of most severe power quality problems that the industrial process has to face [1]. It is defined as a decrease in RMS voltage to between $0.1 \mathrm{pu}$ and $0.9 \mathrm{pu}$ for durations from 0.5 cycles to $1 \mathrm{~min}$, which is usually associated with system faults but can also be caused by switching heavy loads or starting large motors [2]. Most voltage sags are unbalanced event deteriorating the power quality [3]. It can cause voltage sensitive industrial loads to malfunction [4-8], leading to severe economic losses, malfunction of voltage sensitive industrial loads.

Thus, the fast and accurate voltage sequence component detection of unbalanced three-phase system is of major importance for the normal operation of industrial continuous processing. The voltage amplitude can be obtained by Park transformation [9], [10]. The positive- and negative-sequence components become the DC component and second harmonics in the $d q$ synchronous reference frame. Unfortunately, the second harmonics results in long detection time. A novel fast voltage sequence component detector is proposed in this paper. It is to calculate the voltage amplitude projection in $d q$ reference frame rotating with $\mathrm{h}$ times the fundamental angular velocity. Simulation results verify the effectiveness of the algorithm.

\section{PARK TRANSFORMATION}

The unbalanced three-phase system can be expressed as

$$
\left\{\begin{array}{l}
u_{a}=U_{a} \sin \left(\omega_{1} t+\varphi_{a}\right) \\
u_{b}=U_{b} \sin \left(\omega_{1} t+\varphi_{b}\right) \\
u_{c}=U_{b} \sin \left(\omega_{1} t+\varphi_{c}\right)
\end{array}\right.
$$

where $\omega_{1}$ is the fundamental angular velocity, $U_{i}$ and $\varphi_{i}(i=a, b, c)$ are the voltage amplitude and phase angle of phase voltage $u_{i}(i=a, b, c)$, respectively.

The unbalanced voltage can be decomposed into positive- and negative-sequence component. And it can be obtained by symmetrical components in $\alpha \beta$ stationary reference frame as

$$
\left\{\begin{array}{l}
u_{\alpha}=U_{1} \sin \left(\omega_{1} t+\varphi_{1}\right)+U_{2} \sin \left(\omega_{1} t+\varphi_{2}\right) \\
u_{\beta}=-U_{1} \cos \left(\omega_{1} t+\varphi_{1}\right)+U_{2} \cos \left(\omega_{1} t+\varphi_{2}\right)
\end{array}\right.
$$

where $U_{i}$ and $\varphi_{i}(i=1,2)$ are the voltage amplitude and initial phase angle of the positive- and negative-sequence components, respectively.

By Park transformation, the positive- and negativesequence component become the DC component and second harmonic in the $d q$ synchronous rotating reference frame, respectively. And the DC component can be obtained by eliminating the second harmonic which results in large time delay. A novel algorithm is proposed in this paper. It is to project the unbalanced three-phase voltage to the nonsynchronous $d q$ rotating reference frame with angular velocity $h \omega_{1}$. Then, the corresponding $\alpha \beta$ to $d q$ matrix can be expressed as

$$
T_{\alpha \beta / d q}=\left(\begin{array}{cc}
\sin \left(h \omega_{1} t+\varphi_{h}\right) & -\cos \left(h \omega_{1} t+\varphi_{h}\right) \\
\cos \left(h \omega_{1} t+\varphi_{h}\right) & \sin \left(h \omega_{1} t+\varphi_{h}\right)
\end{array}\right)
$$

Thus, the $d q$ components can be obtained shown at the bottom of the page. It can be observed that the positive- and negative-sequence component become the 
$\mathrm{h}-1$ and $\mathrm{h}+1$ harmonic components in the $d q$ reference frame of $h \omega_{1}$ angular velocity, respectively.

\section{MOVING AVERAGE FILTER}

Moving average filter (MAF) is a linear phase finite impulse response filter. Its definition in continuous-time domain is

$$
\bar{u}(t)=\frac{1}{T_{\omega}} \int_{t-T_{\omega}}^{t} u(\tau) d \tau
$$

where $T_{\omega}$ is the filter window width.

Its transfer function can be described as

$$
G_{M A F}(s)=\frac{\bar{u}(s)}{u(s)}=\frac{1-e^{-T_{\omega} s}}{T_{\omega} s}
$$

Substituting $s=j \omega=j h \omega_{1}$ into (6), its amplitude and phase expressions can be obtained as

$$
G_{M A F}(j \omega)=\left|\frac{\sin \left(h \omega_{1} T_{\omega} / 2\right)}{h \omega_{1} T_{\omega} / 2}\right| \angle\left(-\frac{h \omega_{1} T_{\omega}}{2}\right)
$$

where $h$ is the harmonic order, $\mathrm{T}$ is fundamental period, $\omega_{1}=2 \pi / \mathrm{T}$.

With $T_{\omega}=\mathrm{T} / \mathrm{n}$, Equation $\mathrm{G}_{\mathrm{MAF}}(j \omega)=0$ yields the relation $\mathrm{h}=\mathrm{nk}(n=1,2,3 . ., k=1,2,3 \ldots)$. It indicates that $\operatorname{MAF}(\mathrm{T} / \mathrm{n})$ can eliminate all the harmonics of order $\mathrm{h}=\mathrm{nk}$.
For instance, $\operatorname{MAF}(\mathrm{T} / 2)$ can filter out all the $\mathrm{h}=2 \mathrm{k}$ harmonic components. Then the $\mathrm{h}+1$ harmonics in $u_{d q}(t)$ can be eliminated by $\operatorname{MAF}(\mathrm{T} /(\mathrm{h}+1))$ and the corresponding h-1 harmonics can be derived shown at the bottom of the page. (9)and (10) illustrate that the $\mathrm{MAF}(\mathrm{T} /(\mathrm{h}+1))$ results in amplitude reduction and phase shift of the h-1 harmonic component in $d q$ reference frame.

Thus, the voltage amplitude of positive-sequence component can be derived as

$$
U_{1}=\frac{\pi(h-1)}{h+1} \frac{1}{\sin \frac{\pi(h-1)}{h+1}} \sqrt{\bar{u}_{d}^{2}(t)+\bar{u}_{q}^{2}(t)}
$$

The negative-sequence component can also be obtained by utilizing the $\operatorname{MAF}(\mathrm{T} /(\mathrm{h}-1))$ to eliminate the h-1 harmonic components.

Fig.1 shows the detection diagram of the proposed algorithm, where PLL is synchronization unit providing phase information for Park transformation. The estimated fundamental frequency $f_{1}$ is feedback to MAF to improve filtering effect. The detection time is $\mathrm{T} /(\mathrm{h}+1)$. In addition, the negative-sequence component can also be obtained by eliminating the $\mathrm{h}-1$ harmonics with detection time $\mathrm{T} /(\mathrm{h}-1)$.

$$
\begin{aligned}
& \left\{\begin{array}{l}
u_{d}(t)=U_{1} \cos \left((h-1) \omega_{1} t+\varphi_{h}-\varphi_{1}\right)+U_{2} \cos \left((h+1) \omega_{1} t+\varphi_{h}+\varphi_{2}\right) \\
u_{q}(t)=-U_{1} \sin \left((h-1) \omega_{1} t+\varphi_{h}-\varphi_{1}\right)+U_{2} \sin \left((h+1) \omega_{1} t+\varphi_{h}+\varphi_{1}\right)
\end{array}\right. \\
& \bar{u}_{d}(t)=\frac{h+1}{T} \int_{t-T /(h+1)}^{t} u_{d}(t) d t \\
& =\frac{h+1}{\pi(h-1)} \sin \frac{\pi(h-1)}{h+1} U_{1} \cos \left((h-1) \omega t+\varphi_{h}-\varphi_{1}-\frac{\pi(h-1)}{h+1}\right) \\
& \bar{u}_{q}(t)=\frac{h+1}{T} \int_{t-T /(h+1)}^{t} u_{q}(t) d t \\
& =-\frac{h+1}{\pi(h-1)} \sin \frac{\pi(h-1)}{h+1} U_{1} \sin \left((h-1) \omega t+\varphi_{h}-\varphi_{1}-\frac{\pi(h-1)}{h+1}\right)
\end{aligned}
$$

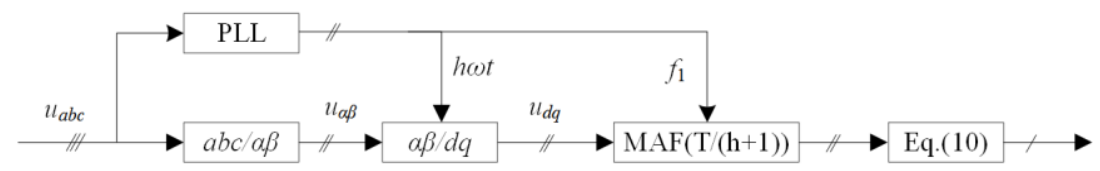

Fig1. Detection diagram of positive-sequence components

It needs to be observed that the positive- and negative sequence components become $\mathrm{h}+1$ and $\mathrm{h}-1$ harmonics by negative Park transformation. Then the detection time of negative-sequence component is $T /(h+1)$.

\section{SIMULATION VERIFICATION}

In order to verify the accuracy of the algorithm, the time domain simulations in MATLAB/Simulink environment were carried out by using $10 \mathrm{kHz}$ discrete fixed-step solver. The per unit (pu) is used in this paper. Fig.2 shows the voltage waveform. At $\mathrm{t}=0.03 \mathrm{~s}$, the positivesequence component is dropped to be $0.6 \mathrm{pu}$.

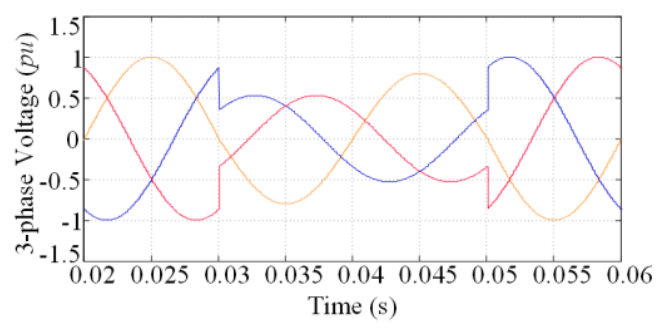

Fig 2. unbalanced three-phase voltage sag 


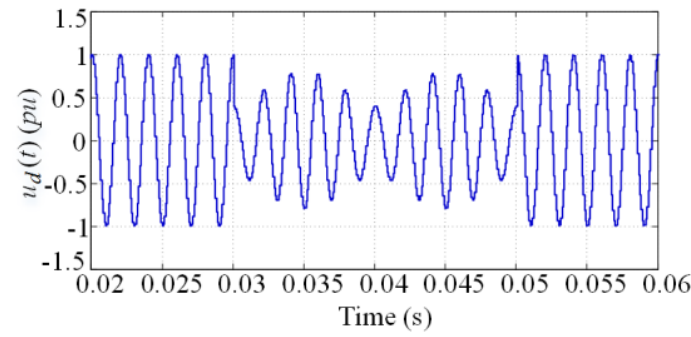

(a)

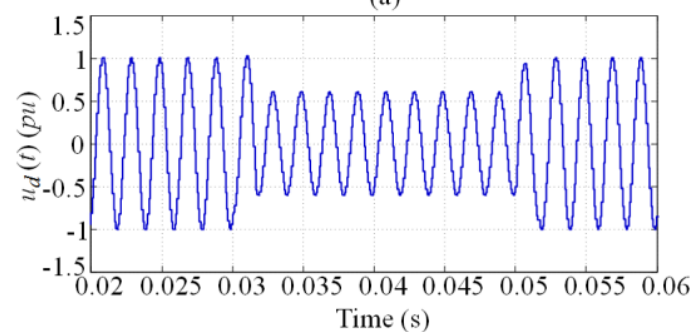

(b)

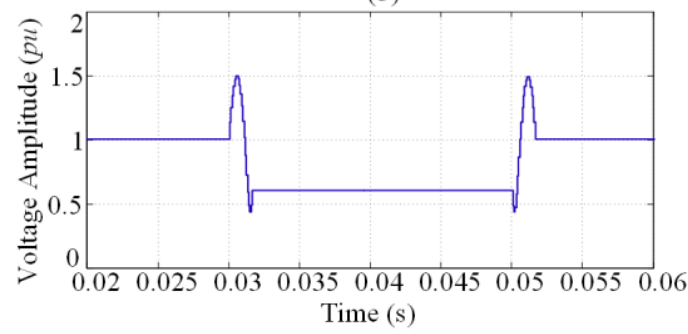

(c)

Fig 3. Detection results. (a) ud(t). (b) $\bar{u} d(t)$. (c) estimated voltage amplitude.

Fig. 3 shows the detection results. The $\mathrm{h}=11$ is utilized in this paper. Fig.3(a) is the $u_{d}(t)$ obtained by Park transformation. It is composed by $\mathrm{h}=10$ and $\mathrm{h}=12$ harmonics. Fig.3(b) is the $\bar{u}_{d}(t)$ filtered by MAF(T/12). It can be observed that there is only $h=10$ harmonic. Fig.3(c) is the estimated voltage amplitude of positive-sequence component. The system detection time is the filter time of MAF which is $T / 12$. It illustrates that the voltage amplitude can be calculated fast and accurately.

\section{CONCLUSIONS}

A novel fast voltage sequence component detector of unbalanced three-phase system is proposed in this paper. It is to calculate the corresponding voltage components in $d q$ rotating reference frame of $h \omega_{1}$ angular velocity. The positive- and negative-sequence components become the $\mathrm{h}-1$ and $\mathrm{h}+1$ harmonics, respectively. As the sequence components become harmonics of high order, the system filter time is reduced substantially. And the voltage can be estimated with fast response. Simulation results verify the effectiveness of the algorithm.

\section{ACKNOWLEDGEMENTS}

This work was supported by the science and technology development program of Shandong Provincial Education Office under Project J15LN10, and the science and technology program of Yantai City under project 2016 ZH055.

\section{REFERENCES}

1. M.H.J. Bollen, "Understanding Power Quality Problems: Voltage Sags and Interruptions", New York: IEEE Press, Vol. 1, 1999.

2. IEEE Std 1159-2009. IEEE Recommended Practice for Monitoring Electric Power Quality.

3. J. Matas, M. Castilla, J. Miret, L. García de Vicuña and R. Guzman, "An Adaptive Prefiltering Method to Improve the Speed/Accuracy Tradeoff of Voltage Sequence Detection Methods Under Adverse Grid Conditions," IEEE Transactions on Industrial Electronics, vol. 61, no. 5, pp. 2139-2151, May 2014.

4. M. H. J. Bollen, T. Tayjasanant and G. Yalcinkaya, "Assessment of the number of voltage sags experienced by a large industrial customer," IEEE Transactions on Industry Applications, vol. 33, no. 6, pp. 1465-1471, Nov/Dec 1997.

5. M. H. J. Bollen and L. D. Zhang, "Analysis of voltage tolerance of AC adjustable-speed drives for three-phase balanced and unbalanced sags," IEEE Transactions on Industry Applications, vol. 36, no. 3, pp. 904-910, May/Jun 2000.

6. J. C. Gomez, M. M. Morcos, C. A. Reineri and G. N. Campetelli, "Behavior of induction motor due to voltage sags and short interruptions," IEEE Transactions on Power Delivery, vol. 17, no. 2, pp. 434-440, Apr 2002.

7. M. Petronijevic, B. Veselic, N. Mitrovic, V. Kostic and B. Jeftenic, "Comparative study of unsymmetrical voltage sag effects on adjustable speed induction motor drives," IET Electric Power Applications, vol. 5, no. 5, pp. 432-442, May 2011.

8. M. Mohseni, S. M. Islam and M. A. S. Masoum, "Impacts of Symmetrical and Asymmetrical Voltage Sags on DFIG-Based Wind Turbines Considering Phase-Angle Jump, Voltage Recovery, and Sag Parameters," IEEE Transactions on Power Electronics, vol. 26, no. 5, pp. 1587-1598, May 2011.

9. Y. Kumsuwan and Y. Sillapawicharn, "A fast synchronously rotating reference frame-based voltage sag detection under practical grid voltages for voltage sag compensation systems," 6th IET International Conference on Power Electronics, Machines and Drives (PEMD 2012), Bristol, 2012, pp. 1-5.

10. G. Chen, L. Zhang, R. Wang, L. Zhang and X. Cai, "A Novel SPLL and Voltage Sag Detection Based on LES Filters and Improved Instantaneous Symmetrical Components Method," IEEE Transactions on Power Electronics, vol. 30, no. 3, pp. 1177-1188, March 2015. 